\title{
Reflexões de agricultores familiares sobre a dinâmica de fornecimento de seus produtos para a alimentação escolar: 0 caso de Araripe, Ceará
}

\section{Reflections by family farmers on the dynamics of providing their products for school food: the case of Araripe, Ceará,}

Brazil

\author{
Amanda de Andrade Marques \\ Mestre em Ciências da Nutrição. \\ E mail: amandanutriळyahoo.com.br \\ Maria das Graças Melo Fernandes \\ Professora Doutora do Programa de Pós-Graduação em Enferma- \\ gem da Universidade Federal da Paraíba. \\ E-mail: graacafernandesळhotmail.com \\ Ivonaldo Neres Leite \\ Centro de Ciências Aplicadas Educação. Professor Doutor. Univer- \\ sidade Federal da Paraíba. Mamanguape, PB, Brasil. \\ E-mail: ivonaldo.leiteœgmail.com \\ Rodrigo Toledo Viana \\ Professor Doutor do Programa de Pós-Graduação em Ciências da \\ Nutrição da Universidade Federal da Paraíba. \\ E-mail: vianna_rodrigo®yahoo.com.br \\ Maria da Conceição R. Gonçalves \\ Professora Doutora do Programa de Pós-Graduação em Ciências \\ da Nutrição da Universidade Federal da Paraíba. \\ E-mail: raulceica®ig.com.br \\ Alice Teles de Carvalho \\ Professora Doutora do Programa de Pós-Graduação em Ciências \\ da Nutrição da Universidade Federal da Paraíba. \\ E-mail: alicetelळterra.com.br
}

\section{Correspondência}

Amanda de Andrade Marques

Rua José Delfino, 29, Bairro Granjeiro, CEP 63109-052, Crato, CE, Brasil.

\section{Resumo}

As transformações ocorridas na sociedade atual refletem diretamente em escolhas alimentares não saudáveis. Como consequência desse padrão alimentar, surgem o sobrepeso e a obesidade, e também doenças crônicas não transmissíveis. O Programa Nacional de Alimentação Escolar (o PNAE) configura uma importante estratégia do Governo Federal para o enfrentamento desse problema alimentar. Desde suas primeiras resoluções, busca-se cada vez mais cardápios saudáveis, regionalizados e adaptados à cultura local. A mais recente normativa do programa obriga estados e municípios a comprarem parte de seus alimentos de agricultores familiares rurais. Este estudo analisa reflexões dos agricultores familiares em relação à dinâmica de abastecimento dos produtos da agricultura familiar para a alimentação escolar. Trata-se de um estudo de caso, realizado segundo a técnica qualitativa por meio de entrevista semiestruturada no município de Araripe, Ceará. Foram entrevistados catorze agricultores familiares que fornecem gêneros alimentícios para escolas e identificadas duas categorias principais nos depoimentos: dificuldades e benefícios. Pode-se perceber que questões relacionadas ao pagamento, ao transporte e a estrutura física destacaram-se como os principais entraves para que essa prática fosse efetivada. Quanto aos benefícios, o mais recorrente foi a oportunidade de emprego que esse mercado trouxe. Os resultados indicam a necessidade de 
ações por parte da gestão local para reconhecer o potencial agrícola dessa região, além de estabelecer parcerias com outros órgãos, com vistas a melhorar a capacitação desses agricultores e subsidiá-los no atendimento às especificações legais do programa. Isso pode contribuir para o aumento da renda e da qualidade de vida entre as famílias rurais.

Palavras-chave: Agricultores Familiares; Alimentação Escolar; Programas de Alimentação e Nutrição.

\section{Abstract}

Changes taking place in society today reflect directly on unhealthy food choices. As a consequence of this new eating pattern, overweight and obesity emerge, as well as noncommunicable chronic diseases. The National Programme for School Food (PNAE) constitutes an important strategy of the Federal Government to tackle this eating problem. Since its early resolutions, there is a continued search for menus increasingly healthy, regionalized, and adapted to the local culture. The latest standards of the program provide that the states and municipalities should purchase some of their food from rural family farmers. This study analyzes reflections by family farmers with regard to the dynamics of providing family farm products for school food. This is a case study, conducted according to the qualitative technique by means of a semi-structured interview in the town of Araripe, Ceará, Brazil, where fourteen farmers who provide foodstuffs for schools were interviewed. Two main categories were identified in the accounts: difficulties and benefits. We can notice that issues related to payment, transportation, and physical structure stood out as major obstacles to accomplish this practice. Regarding the benefits, the most recurrent thing was the job opportunity brought by this market. The results indicate the need for actions on the part of local management to recognize the agricultural potential of this region, in addition to establish partnerships with other agencies, in order to improve the training of these farmers and provide them with means to comply with the legal requirements. This may contribute to increase the income and quality of life among rural families.

Keywords: Family Farmers; School Feeding; Food and Nutrition Programs. 


\section{Introdução}

Um novo padrão alimentar tem surgido na sociedade nas últimas décadas, caracterizado pela ingestão de alimentos com elevada carga de processamento, ricos em gordura, açúcar e sal. Como consequência desse modelo, surgem o sobrepeso, a obesidade e as doenças crônicas não transmissíveis (Sarti e col., 2011). Com o intuito de reverter esse problema, o governo brasileiro investe em políticas públicas como o Programa Nacional de Alimentação Escolar (PNAE).

O PNAE é o programa de suplementação alimentar mais antigo, de maior abrangência e continuidade do Brasil. Em 2012, movimentou R\$ 3,3 bilhões para beneficiar 45 milhões de estudantes da educação básica, além de jovens e adultos (FNDE, 2013). Sua instituição legal, na década de 1950, decorreu de ações da sociedade civil com o objetivo de combater a desnutrição infantil e de algumas experiências isoladas em estados e municípios (Turpin, 2009).

Desde sua concepção até os dias atuais, o programa tem passado por modificações em sua operacionalização e são percebidos avanços importantes em relação à(s) abrangência, gestão, conformação dos cardápios, diretrizes e articulação com outros setores além da educação (Teo e Monteiro, 2012). Desde 2005 , a alimentação escolar faz parte dos eixos articuladores da Política Nacional de Segurança Alimentar e Nutricional (PNSAN) e do Direito Humano à Alimentação Adequada (DHAA), alterando de forma significativa seu paradigma, inclusive a forma do atendimento (Carvalho, 2009).

Em 2009, a legislação do PNAE foi revisada com a aprovação da Lei n. 11.947, que abre um precedente histórico para a agricultura familiar brasileira. Essa lei ampara o setor em seu artigo 14, uma vez que explicita o apoio à agricultura familiar com a aquisição de produtos destinados à alimentação escolar (Brasil, 2009).

Nesse sentido, a relação entre a escola e a agricultura familiar poderá contribuir para relacionar o consumo à produção de alimentos mais sustentáveis, estreitando a relação entre cidade e campo. Além disso, há vantagens nesse processo, tendo em vista a possibilidade de diminuir os custos com transporte e aprimorar a qualidade e confiabilidade dos alimentos, além de aumentar a identificação com hábitos de consumo saudáveis (Triches e Schneider, 2010).

Até meados dos anos 2000, a agricultura familiar era caracterizada por muitos autores como "pequena produção", unidades de subsistência que comercializavam em nível local o excedente produzido. Um estudo realizado pelo convênio entre a Organização das Nações Unidas para Alimentação e Agricultura (FAO) e o Instituto Nacional de Colonização e Reforma Agrária (Incra), em conjunto com o Ministério do Desenvolvimento Agrário, denominado Novo retrato da agricultura familiar: o Brasil redescoberto, apresentava a importância e a contribuição da agricultura familiar para o Brasil (Guanziroli e Cardim, 200o; Guanziroli e col., 2012).

Para Guanziroli e colaboradores (2012), o termo agricultor familiar não deve ser visto como superior, em detrimento do agricultor não familiar. A designação envolve a caracterização da categoria que utiliza mão de obra familiar e que exerce a gestão do empreendimento de forma direta, presencial, por meio de algum dos familiares envolvidos na produção.

Dados do último Censo Agropecuário, realizado em 2006, apontam a agricultura familiar como responsável por parte considerável do abastecimento alimentar nacional. Em 2006, o valor bruto da produção dos agricultores familiares foi de R\$ 59,2 bilhões, correspondente a 36,11\% da produção agropecuária total (IBGE, 2006). No entanto, apesar desses dados, os agricultores familiares não encontram tanta facilidade para acessar as redes de comércio, havendo a necessidade de estabelecer "elos" para que se vinculem a agentes econômicos e sociais (Kageyama e Hoffmann, 2007; Turpin, 2009).

$\mathrm{O}$ agricultor familiar e/ou suas organizações são atores-chave para efetivar o processo de aquisição de produtos para a alimentação escolar. A legislação vigente do PNAE direciona os agricultores no sentido de organizar e investir na produção, na capacidade de atender à demanda das escolas, na necessidade da articulação com outros agricultores familiares sob a forma de associações/cooperativas, objetivando, assim, agregar valor aos seus produtos (Brasil, 2009).

Esse novo mercado aberto para o setor agrícola familiar exige um posicionamento diferenciado quanto à produção. Agora, é necessário que esta seja adequada do ponto de vista nutricional, da qualidade 
e da quantidade. Além disso, os agricultores deverão adaptar-se a uma nova lógica de mercado, o chamado mercado institucional ${ }^{1}$.

Antes dessa prerrogativa legal, já existiam algumas experiências de compra e venda de produtos da agricultura familiar, por meio do Programa de Aquisição de Alimentos (PAA) ou da legislação municipal que indicava a viabilidade dessa iniciativa. 0 boletim de desempenho elaborado pela organização não governamental (ONG) Fome Zero, em 2007, traz uma visão geral dessa situação no país. Percebe-se, a partir desse documento, a baixa adesão dos municípios e estados à compra de gêneros da agricultura familiar para abastecer suas escolas. Desde 1998, já existia uma mobilização para esse tipo de compra em municípios como Rolante e Dois Irmãos, no Rio Grande do Sul (Triches e Schneider, 2010). Porém, essas ações eram pontuais e dependiam muito mais da vontade política e do incentivo da gestão municipal.

Assim como em municípios da região Sul, o município de Araripe, no Ceará, região Nordeste, iniciou as compras da agricultura familiar por meio do PAA, em 2007. Portanto, os agricultores já estavam organizados formalmente no primeiro ano após o estabelecimento desse tipo de compra, em 2010. Além disso, a atividade econômica é predominantemente agrícola, com destaque para o algodão arbóreo e herbáceo, a banana, o milho e o feijão. Foram identificados 1.650 agricultores em Araripe e, destes, 1.392 são enquadrados na categoria familiar. Os agricultores se organizam por meio de unidades associativas, que totalizam 64 e, destas, apenas 3 fornecem gêneros alimentícios para as escolas municipais.

Diante das modificações nas normas que regem o PNAE, direcionando parte das aquisições de gêneros alimentícios do programa para os produtos da agricultura familiar, este artigo analisa as reflexões de agricultores familiares relativas à dinâmica de abastecimento de seus produtos para a alimentação escolar em Araripe.

\section{Material e métodos}

Para investigar essa temática, adotou-se o estudo de caso com abordagem qualitativa. O universo de pesquisa foi constituído pelos 28 agricultores familiares de Araripe que fornecem produtos para a alimentação escolar (produtos hortifrutigranjeiros, iogurte, queijo, pão de queijo, bolo e tapioca). Destes, 14 foram sorteados aleatoriamente. Esses agricultores familiares fazem parte de 3 associações.

As informações foram obtidas por meio de entrevistas semiestruturadas, após assinatura do termo de consentimento livre e esclarecido pelos agricultores incluídos no estudo. O instrumento de coleta de dados foi elaborado com base nos objetivos do estudo. As perguntas foram distribuídas nos seguintes eixos: Delimitação do universo familiar; Tipo de organização e de associação na qual o agricultor estava inserido; Produção e distribuição dos gêneros alimentícios para as escolas. No eixo Produção e distribuição dos gêneros alimentícios, entre outros questionamentos, foram captadas as reflexões dos agricultores em relação às dificuldades e aos benefícios percebidos no que diz respeito ao fornecimento dos gêneros alimentícios para as escolas. As entrevistas, gravadas, foram realizadas individualmente no local de trabalho de cada agricultor.

O instrumento foi pré-testado em município diferente do pesquisado para avaliar sua aplicabilidade e confiabilidade. Participaram dessa etapa 11 agricultores familiares que faziam parte de uma cooperativa de fornecedores de leite pasteurizado, bebida láctea e frango para as escolas municipais. As entrevistas foram realizadas individualmente na sede da cooperativa.

Os dados foram analisados de acordo com os passos da Análise de Conteúdo temática, com as seguintes fases: Pré-análise; Exploração do material; e Interpretação dos depoimentos.

Na Pré-análise, o material foi organizado e foi realizada uma "leitura flutuante" das informações

1 Mercado institucional: aquele que envolve as três esferas governamentais (municipal, estadual e federal) em todas as suas operações de compra de alimentos, sejam as compras de caráter contínuo (creches, escolas, hospitais) ou as aquisições de caráter esporádico (aquelas que atendem às populações em casos de calamidade pública e as referentes às políticas de Estado e programas de governo) (Maciel, 20o8). 
coletadas (análise e conhecimento do texto, retomando objetivos, pressupostos e hipóteses). Nessa fase foi definida a "constituição do corpus" para cada entrevista, organizando as informações coletadas quanto à: validade qualitativa, como a exaustividade, considerando todos os aspectos levantados em cada pergunta; representatividade, garantindo a participação de cada grupo estudado; homogeneidade, tendo assegurado a mesma técnica de coleta e pertinência, para que o material de cada entrevista mostre-se adequado em relação aos objetivos do estudo (Minayo, 2010; Bardin, 2011). Após essa etapa inicial, foram definidas as unidades de registro, ou núcleos de sentido (palavras-chave ou frase), e as unidades de contexto (parágrafo da entrevista no qual se localiza o núcleo de sentido) (Minayo, 2010; Bardin, 2011).

Na denominada Exploração do material, o objetivo foi identificar o núcleo de compreensão do texto para alcançar as categorias temáticas.

Por fim, na Interpretação dos depoimentos foi realizada a distribuição das categorias temáticas identificadas, com sua interpretação e discussão à luz do referencial teórico (Minayo, 2010; Bardin, 2011).

O estudo foi aprovado pelo Comitê de Ética em Pesquisa do Centro de Ciências da Saúde da Universidade Federal da Paraíba (UFPB), sob o Protocolo n. 339/11.

As categorias utilizadas foram definidas a partir do sentido observado nas falas (material transcrito) dos agricultores familiares e da interação direta com o material empírico (observação in loco). Trata-se de duas categorias (dificuldades e benefícios) e as reflexões elaboradas em torno delas. Quanto às dificuldades, temos: 1) pagamento; 2) transporte; 3) estrutura física. Quanto aos benefícios, temos: 1) oportunidade de emprego. Visando o anonimato dos participantes no estudo, para a apresentação dos resultados criou-se uma identificação. "Agricultor" seguido de um número que varia de 1 a 14 (número de agricultores entrevistados).

\section{Resultados e discussão}

Os depoimentos dos agricultores familiares apontaram o fato de que as dificuldades não estão relacionadas à entrada no processo, mas, sim, a se manter nele. As reflexões em torno da primeira categoria, dificuldades, apontam o fato de que os agricultores familiares, apesar de ter capacidade produtiva para escoar sua produção para as escolas municipais, preferem permanecer fora desse mercado. A fala a seguir é um exemplo disso. A agricultora participa de uma associação de fornecimento de iogurte e queijo para a alimentação escolar; ela afirma ter capacidade produtiva para vender macaxeira, porém, devido aos atrasos, desiste:

Já pensei em vender a macaxeira, botar macaxeira pravender [...] aí, meu esposo diz que demora muito o pagamento. Ele disse pra botar coisa pra vender pra demorar o pagamento, como estamos assim! Nós ficamos dois meses, já entramos no terceiro sem pagamento, aí, às vezes, nós temos precisão. (Agricultora E2)

O gerenciamento do PNAE é de responsabilidade das três instâncias governamentais: municípios, estados e Governo Federal. O Ministério da Educação (MEC), via Fundo Nacional do Desenvolvimento da Educação (FNDE), repassa valores fixos por aluno; cabe aos municípios e estados complementar esses valores por meio de contrapartidas financeiras. A transferência do recurso federal é realizada em dez parcelas mensais, a partir de fevereiro, correspondendo a 200 dias letivos (FNDE, 2013). Portanto, o recurso financeiro destinado a adquirir os gêneros alimentícios para o programa, inclusive da agricultura familiar, está disponível mensalmente nas contas dos municípios.

A referida normativa completa 5 anos da publicação em 2014. Não se justifica que ainda haja desconhecimento do potencial agrícola da região por parte dos responsáveis. O planejamento dos cardápios deveria incluir um levantamento dos agricultores familiares aptos e com capacidade produtiva, a sazonalidade dos itens, a vocação agrícola e os hábitos alimentares. Além disso, gêneros in natura e que são característicos da identidade alimentar local, como a macaxeira, poderiam fazer parte do cardápio escolar. O Guia alimentar da população brasileira recomenda a utilização de raízes e tubérculos, por seu conteúdo de carboidratos complexos e por ser compostos de proteínas e vitaminas do complexo B, além de outras vitaminas, minerais, ácidos graxos essenciais e fibras alimentares (Brasil, 2005). 
Estudos como o de Saraiva e colaboradores (2013) sustentam que ainda há muito a ser feito para consolidar o processo de compra e venda dos produtos agrícolas para a alimentação escolar. As entidades executoras (prefeituras ou secretarias de educação) precisam, entre outras questões, apropriar-se das realidades agrícolas locais e regionais para que o aluno tenha a possibilidade de acessar os diversos tipos de alimento.

O estudo de Carvalho (2009) corrobora que alguns agricultores têm potencial para participar desse processo, no entanto, fatores como falta de divulgação dos editais pelos órgãos públicos; atrasos e contratempos nos pagamentos; crença de que o governo não cumpre com seus compromissos nos prazos estipulados; e falta de crédito e incentivos fiscais para atender à demanda afastam esses agricultores do mercado de alimentação escolar. Acredita-se, ainda, que os gestores têm a função de desmistificar a ideia de Estado "mau pagador" por meio de convênios com outros órgãos.

Em um estudo realizado em Araraquara-SP (Almeida e col., 2009), constatou-se que os principais produtos comprados dos agricultores familiares foram mandioca, milho, abóbora, hortaliças, frutas e legumes da época. Parte deles é destinada via PAA para alimentação escolar, no entanto, os autores afirmam que a representatividade do volume desses alimentos ainda era baixa. Analisando os entraves institucionais e organizativos encontrados para que essa prática fosse efetivada no município em questão, destaca-se a redução do número de produtores participantes por conta da demora do repasse de pagamentos devido a problemas burocráticos, dificuldades dos produtores para levar o produto até o local indicado e produtores que não se organizam em associações ou cooperativas, entre outros.

Os Conselhos de Alimentação Escolar (CAE), criados em 1994, a partir da descentralização do PNAE, tem como uma de suas funções analisar, acompanhar e fiscalizar a aplicação dos recursos transferidos às entidades executoras do programa. São constituídos por 7 membros titulares, sendo 1 representante do Poder Executivo, 2 representantes dos professores, alunos (maiores de 18 anos) ou profissionais da educação, 2 representantes de pais de alunos e 2 representantes de outro segmento da sociedade civil organizada (FNDE, 2013; Gallina e col., 2012). Esse espaço de participação que afirma o controle social constitui uma oportunidade para que a comunidade escolar e os agricultores familiares discutam as questões relacionadas ao pagamento e, assim, cobrem uma posição da administração municipal.

A iniciativa do Governo Federal de inserir a produção local em um programa complexo, como é o caso do PNAE, e por se tratar de uma estratégia de segurança alimentar e nutricional (SAN), ao promover o DHAA por meio da alimentação escolar, exige uma articulação entre os setores escolares e agrícolas, além de condições favoráveis nas diversas instâncias envolvidas (Villar e col., 2013).

Ainda em relação ao tema pagamento, a fala a seguir demonstra a responsabilidade do agricultor quanto ao cumprimento do contrato com a prefeitura; além disso, indica a necessidade de superar a ideia pré-concebida da desconfiança de lidar com uma gestão má pagadora:

Você passa de três a quatro meses sem receber. Sempre foi assim, desde o início. Se eles pagassem todo mês, certo, era bom demais [...] Às vezes, a gente tem que sacrificar as economias da gente pra poder manter o compromisso. (Agricultura $\mathrm{E}_{7}$ )

No município de Concórdia-SC (Turpin, 2009), agricultores familiares afirmaram que o compromisso de entregar semanalmente os produtos da merenda escolar os profissionalizou, já que passaram a gerir melhor seu negócio. Além disso, o aprendizado levou a um fortalecimento da cooperativa de agricultores e estabeleceu uma aproximação com a administração municipal.

Outra reflexão que surgiu nessa categoria foi a falta de transporte específico da entidade executora para entregar nas escolas os gêneros alimentícios produzidos pelos agricultores. Estes têm a responsabilidade de arcar com sua produção e com todas as fases da dinâmica de entrega. No entanto, em suas falas, percebe-se uma inquietação, por terem "um gasto a mais" ao custear as entregas semanais:

A gente não tem transporte. A gente fazé pagar, não é? Carroceiro pra carregar, entregarnas escolas, [...] Se a gente tivesse um transporte pra transportar [...] era bom. (Agricultora E2) 
Alguns autores afirmam que uma dinâmica melhor para o abastecimento dos produtos agrícolas nas escolas estreitaria a relação entre campo e cidade, aproximando, assim, produtores de consumidores, além de proporcionar aos alunos o acesso a uma alimentação regionalizada e mais natural, dando preferência aos alimentos agroecológicos (Brasil, 2009; Maluf, 2009). No entanto, o que se percebe é que alguns dos alimentos fornecidos são do tipo semielaborado, que apresentam um nível de processamento, tornando-os cada vez mais industrializados. Essa situação apesentada pode vir a afastar-a realidade do objetivo dessa iniciativa. Em Araripe, grande parte da produção familiar destinada às escolas provém de alimentos semi-processados ou semielaborados (iogurte, pão de ló, pão de queijo, sequilho, bolo, tapioca) ${ }^{2}$. Esse fato pode decorrer do fator clima, sendo a produção desse tipo de alimento, talvez, a única alternativa encontrada pela entidade executora para atingir os $30 \%$ recomendados pela resolução do FNDE.

Uma característica desses agricultores fornecedores é que a maior parte reside na cidade e desenvolve outras atividades além da agricultura (comércio, artesanato, serviços públicos), não sendo suas atividades econômicas ligadas exclusivamente ao cultivo. É o que Buainain e colaboradores (2003) denominam "novo agricultor familiar", o qual também desenvolve atividades e reside na zona urbana, ou seja, sua vida não está ligada apenas ao trabalho no campo, devido à necessidade de buscar novas alternativas de sustento. Outro fator que o leva a não permanecer no campo é o clima. A seca no Nordeste o obriga a buscar alternativas de sobrevivência.

A proximidade das associações de agricultores familiares com as escolas situadas na cidade pode ser considerada um fator positivo no que se refere, por exemplo, à logística de entrega dos produtos, uma vez que os produtores precisam subsidiar o transporte. Porém, em escolas localizadas na área rural, os alimentos semielaborados, produzidos nas associações localizadas na cidade, não chegam com a mesma facilidade ou não são inseridos no cardápio.
A fala de uma agricultora sugere que a prefeitura arque com o transporte, para que a renda com a venda dos produtos não seja comprometida:

Às vezes, o transporte que leva essa merenda pras escolas, a gente paga por ele, $R \$ 15$,oo cada viagem. Então, eles poderiam deixar um carro pra vir fazer essas entregas pra gente, pra não ter essa dificuldade de estar pagando, às vezes, a moto dá o prego, outras vezes é o reboque que também quebra e fica aquela confusão pra entregar a merenda no horário certo pras crianças. (Agricultora $\mathrm{E}_{5}$ )

Os municípios, por vezes, recebem recursos federais para investir em programas. Uma alternativa encontrada para o problema do transporte de gêneros alimentícios em Concórdia-SC foi a compra de um veículo para transportar os produtos, com recursos advindos do Programa Fome Zero (Turpin, 2009).

Em outra fala, no entanto, o transporte (motoqueiro) financiado pela associação fornecedora de queijo e iogurte para entregar os produtos nas escolas foi considerado uma solução positiva, já que, em outros tempos, as dificuldades eram diferentes:

[...] já foi bem pior, nós contratamos um produtor de leite, que traz leite pra gente também, ele arrumou um reboque pra moto dele e [él ele quem transporta a nossa merenda. O problema, antes, era o transporte, nós sofremos muito no começo porque não tinha quem levasse. Um dia, a Secretaria [de Educação] mandava, outro dia o motorista tinha que ir pra outros lugares... então, a melhor solução foi essa, de arranjar esse rapaz. Ele traz o leite pra gente e faz nossas entregas. (Agricultora E4)

Em meio às dificuldades encontradas, os agricultores associados buscaram alternativas para não deixar de fornecer seus produtos às escolas.

Os produtos semielaborados (queijo, iogurte, bolo, tapioca e pão de queijo) são produzidos de forma artesanal, em casas alugadas pelas associações de agricultores, a maioria sem estrutura física adequada para tal fim. Ainda em relação às dificuldades, muitos agricultores falaram da estrutura física inadequada para a produção dos gêneros alimentícios,

2 Produto de origem vegetal ou animal com matéria-prima que necessita sofrer tratamento e/ou transformação física, química ou biológica, adicionado ou não substâncias permitidas. 
vista como uma possibilidade de comprometer a regularidade das entregas dos produtos, como afirmam algumas dessas agricultoras, que fazem parte de uma associação fornecedora de iogurte e queijo:

Porque a gente já tá parando por falta do fogão, que está num estado lá que só vendo! As panelas que a gente tem lá são emprestadas. Então, pra gente, só tá faltando chegar um repasse [financeiro], aí, a gente vai poder comprar as coisas que estão faltando, porque senão vai parar, não tenho nem medo, nós [ainda] não paramos porque somos teimosas. (Agricultora E2)

A gente tem o fogão todo "encarvoado", o freezer é emprestado. Tudo da gente, a maioria das coisas, é emprestado. (Agricultora E13)

$\varepsilon$ porque, assim, as coisas que nós temos lá são todas emprestadas. O fogão não presta, é um sacrifício com aquele fogão. (Agricultora E11)

Entre os principais entraves indicados pelas entidades executoras de municípios brasileiros de todas as regiões para o não cumprimento do percentual mínimo de 30\%, em 2010, destacou-se a impossibilidade da emissão da nota fiscal, as condições higiênico-sanitárias inadequadas e a inviabilidade de fornecimento regular e constante, sendo esta última justificativa mais presente nas regiões Norte e Nordeste (Saraiva e col., 2013). O planejamento e a organização das entidades locais envolvidas nesse processo podem minimizar o problema do fornecimento irregular e inconstante. Municípios que apresentam expressiva atividade agrícola podem organizar seus produtores de maneira que a distribuição dos gêneros alimentícios seja rateada entre vários agricultores e associações.

O recurso repassado pelo FNDE a estados, municípios e ao Distrito Federal deve ser destinado apenas ao fornecimento de produtos para a alimentação escolar. Os demais gastos relativos ao PNAE devem ser arcados pela administração local, tendo em vista que se trata de um programa descentralizado (FNDE, 2013).
Em geral, os alimentos são produzidos pelas associações em casas alugadas, apenas uma delas tem sede própria. Em mais algumas falas identifica-se a preocupação em comprometer parte do ganho com custos adicionais, ou seja, o que os agricultores estão recebendo na associação é rateado para arcar com outras despesas, como aluguel, água e energia. Ao final, eles não consideram ganhar o suficiente para o sustento de suas famílias, como se observa nas falas a seguir:

Uma dificuldade também é a cozinha, nós temos muita vontade de ter uma cozinha pra trabalhar. Porque a gente ganha pouco, aí, paga RS 250,oo de aluguel, água e luz. (Agricultora $\mathrm{E}_{5}$ )

A cozinha comunitária a gente não tem, a gente paga aluguel, se não pagasse aluguel recebia até mais um dinheirinho. (Agricultora E13)

A gente paga aluguel, água e luz, a luzécara, quase $R S$ 10o,oo. (Agricultora E11)

Porque a gente paga aluguel, aqui, com o trabalho, é dividido pra nós cinco, tudo é dividido, água, luz, aluguel, as coisas são compradas, depende do tanto que a gente ganha, às vezes, a gente fica é quase sem nada, porque tem que pagar pra voltar a comprar. (Agricultora E4)

Além dos produtos citados, adquiridos dos agricultores familiares (semielaborados), há um único produtor familiar que fornece parte das frutas, verduras e legumes. No entanto, a quantidade produzida não é suficiente para atender o contingente de escolas. Na sua área, o plantio é realizado por meio de mandala agrícola 3 . Questionado durante a entrevista a respeito do problema da seca, que aflige o homem do campo, o agricultor respondeu que, da maneira como é realizada sua produção, a chuva é que seria um problema:

[...] na verdade, pra irrigação, esse tempo [seco] é bom, no inverno não é que é ruim, não, é péssimo pra irrigação. (Agricultor E6)

\footnotetext{
3 Mandala, ou Projeto Holístico de Produção e Sustentabilidade Ambiental Mandala (baseado na filosofia indiana), é um sistema de irrigação comunitária baseado em canteiros ao redor de uma fonte de água. O projeto teve origem no Serviço Brasileiro de Apoio às Micro e Pequenas Empresas (Sebrae) da Paraíba e hoje é implementado por uma série de entidades no sertão nordestino.
} 
A principal dificuldade para manter o compromisso de fazer as entregas nas escolas não depende da natureza:

A dificuldade da irrigação é a bomba que não tá dando pra irrigar... pra poder aumentar a produção, precisa de uma bomba mais potente, porque com uma bomba mais potente joga água mais rápido, irriga mais depressa e tem como aumentar a produção. (Agricultor E6)

O contrato desse agricultor foi assinado, porém, ele não consegue entregar a quantidade exigida pela prefeitura às escolas:

Porque é assim, às vezes, tem semana que dá pra entregar, mas não adianta eu entregar [em] uma semana e na outra semana, não. Tem que ter! Você entregar e não faltar! Porque prejudica os cardápios que elas fazem lá na merenda delas, porque segunda-feira é isso aí, por exemplo, não ter aquilo ali, atrapalha! (Agricultor E6)

Nota-se, nesse depoimento, que o agricultor percebe a importância da regularidade das entregas para que os cardápios sejam cumpridos.

O contrato dos agricultores é assinado e, então, ficam estabelecidas as quantidades que serão entregas anualmente. Porém, torna-se inviável que alguns dos gêneros alimentícios estejam disponíveis nas quantidades necessárias em todos os meses do ano. Esse fator pode favorecer o não cumprimento do cardápio mensal das escolas, a redução da qualidade dos cardápios ou o atraso na preparação da merenda.

A lógica de comercialização dos pequenos produtores rurais é diferente daquela das grandes empresas que, historicamente, fornecem os produtos da alimentação escolar, já adaptadas a esse processo. 0 agricultor familiar entrou recentemente nesse mercado e precisa entender seu funcionamento, não apenas as questões burocráticas, mas o que se espera alcançar com essa iniciativa. A qualidade do alimento que ele fornece interfere na saúde dos alunos e a regularidade das entregas é fundamental, entre outros fatores.

Os preços de referência praticados pelas entidades executoras devem considerar aqueles praticados pelo PAA, além disso, não podem ser inferiores aos produtos cobertos pelo Programa de Garantia de Preços para a Agricultura Familiar (PGPAF). Nas localidades em que não houver PAA, os preços de referência devem ser calculados com base no valor da aquisição anual. Nessa questão, o preço pago pelos gêneros alimentícios, na visão dos agricultores, não corresponde ao que eles realmente valem:

o ponto negativo é [que] eles querem um produto de qualidade, de excelente qualidade, mas o preço não equivale, o preço que eles pagam não equivale ao que eles pedem. Por que os produtos que usamos [...] a goma éboa, os produtos são bons. (Agricultora E7)

o prefeito compra, mas compra barato demais. (Agricultora E1)

A matéria-prima onerosa pode ter sido decorrente do período de estiagem nos meses iniciais de 2012, como afirma uma agricultora que vende tapioca:

Quando você compra a goma, tá cara demais! "Cento e pouco" o saco de goma. Você compra a margarina, o açúcar... tudo caro! Tá caro por causa da seca também, o inverno foi muito pouco. (Agricultora E7)

Os preços pagos pelas entidades executoras deveriam ser atualizados semestralmente, além de levar em consideração fatores climáticos, inflação sobre os produtos, salário-mínimo e outras questões. A seca encarece as matérias-primas em algumas regiões do semiárido nordestino. Esse pensamento é evidenciado na seguinte fala:

[...] porque os produtos eram mais baratos. A goma, por exemplo, no início era $R \$ 8$ o, oo o saco, hoje em dia nós compramos de R\$140/13o,oo [...] e também, assim, todos os anos o salário sobe, as coisas, os produtos sobem e nunca os preços dos produtos que nós vendemos sobem, né? Tem tudo a ver! (Agricultora E8)

Essa recente normativa ampara o produtor rural, na medida em que garante que seus produtos sejam vendidos a um programa do porte do PNAE. De fato, as entidades executoras e os agricultores envolvidos nesse processo precisam estar organizados antes mesmo do lançamento da chamada pública. Essa organização refere-se ao conhecimento do potencial agrícola do município, dos agricultores capacitados e comprometidos com essa iniciativa, dos nutricionistas em estreita relação com os produtores e os gêneros alimentícios da agricultura familiar.

O consumo de alimentos advindos da agricultura 
familiar e de suas organizações pode ser uma possibilidade viável para inserir socialmente setores que foram excluídos ao longo da história do país, como é o caso dos agricultores familiares, uma vez que sua produção é consumida pelos alunos, gerando mais renda e mais emprego para os produtores. A Lei 11.947/2009 e a Resolução 38 do FNDE estimulam a organização dos agricultores em associações ou cooperativas. Tornar-se parte de um grupo exige espírito de coletividade, confiança, aprendizado, companheirismo. A cooperação, o diálogo, entre eles deve superar o individualismo, que pode prejudicar o bem comum e o acesso a esse mercado.

As políticas públicas de alimentação e nutrição pensadas sob a ótica da SAN e da garantia do DHAA, como é o caso do PNAE, tem como característica marcante a intersetorialidade das ações e a participação de vários setores em um mesmo programa (educação, saúde, agricultura, controle social). Porém, se não houver de fato uma integração entre setores e objetivos comuns, o que pode ocorrer é que interesses individuais prevaleçam em detrimento da ideia inicial do programa.

Estudo realizado em regiões brasileiras por Martins e Cavalcanti (2007) apontou algumas dificuldades para que os agricultores acessassem o programa, entre elas a documentação exigida, a qualidade da produção, a falta de adequação entre o calendário e o programa e a capacidade agrícola. Esses entraves para a efetivação dessa política ainda persistem em alguns municípios, mesmo 5 anos após a promulgação da Lei n. 11.947/2009.

As dificuldades descritas precisam ser superadas para efetivar a inserção do produtor rural no PNAE e garantir a oferta de alimentos saudáveis com regularidade, assegurando, assim, o DHAA e a SAN dos alunos. As motivações para tal não são restritas à vontade política, mas constituem diversas ordens, tendo em vista a complexidade do tema.

Em relação aos benefícios, nas falas dos agricultores fica evidente que o mercado da alimentação escolar é atraente, mas não suficientemente seguro e rentável para se investir na produção e, ao mesmo tempo, gerar renda. A inserção dos produtos da agricultura familiar na alimentação escolar ampliou o número de fornecedores do programa e abriu o precedente da dispensa de licitação e a possibilidade de negociar e vender seus produtos sem intermediadores (Brasil, 2009). Essa visão é confirmada no depoimento a seguir:

Porque pelos menos tem como vender, num vende pra atravessador, vende direto, né? (Agricultora E3)

Esse novo mercado garantiu um trabalho fixo, "garantido", como os agricultores relatam, dinamizando a economia da cidade. Apesar de admitir "ser pouco" o que recebem, eles consideram importante a continuidade desse serviço para subsidiar as despesas de casa, como pode ser observados no seguinte depoimento:

Até agora, eu não tenho vontade de desistir, por mais que a gente trabalhe só pra pagar, eu não desisto, porque é o único trabalho que eu tenho durante esse tempo. Sempre trabalhava em casa de família, aí, hoje, eu trabalho aqui, às vezes, à tarde até dez da noite [...] aí, é a ajuda que eu tenho por enquanto. (Agricultora $\mathrm{E}_{4}$ )

Embora considerem pouco o que ganham, ficam satisfeitos por ter uma ocupação garantida e estar incluídos socialmente.

Muitos desses agricultores já estavam aposentados, trabalhavam em casas de família, faziam trabalhos informais e sem garantia alguma de retorno financeiro, moravam nos sítios, dependendo exclusivamente do que produziam na propriedade:

$\varepsilon$ como eu disse, tenho uma ocupação. Porque a pessoa ficar só dentro de casa sem fazer nada, quem trabalhou a vida inteira. (Agricultora $\mathrm{E}_{3}$ )

Foi bom porque antes disso eu só tinha o meu dinheirinho, se eu fizesse bolo confeitado, salgado, aí, era quando apareciam essas coisas. Agora, eu tenho meu dinheiro! (Agricultora E11)

Os agricultores consideram que esse dinheiro é uma "ajuda”, uma complementação necessária. Mesmo assim, falam em "falta de opção":

Ajudou mais [no] nosso alimento de dentro de casa. Porque é um dinheirinho a mais, ajudou bastante [...] Por que é que ainda hoje eu estou aqui? Porque eu num tenho outra opção e o que tem é isso aqui [...] e me serve bastante, assim mesmo. (Agricultora E9) O emprego que eu posso arrumaréesse. Eu não tenho curso alto pra arrumar emprego. (Agricultora E1) 
Prezotto (2002) afirma que a agroindústria familiar rural pode ser uma alternativa viável para reverter as condições sociais vivenciadas no campo. Impulsionando direta e indiretamente novas alternativas de trabalho e renda. 0 que seria concebida como sendo uma inclusão sócio-econômica dos agricultores familiares.

Em Dois Irmãos-RS, o processo licitatório de compras públicas favorecia apenas o mercado varejista e atacadista, havia pouca preocupação com a qualidade dos produtos oferecidos às crianças. Em 2009, passou-se a utilizar 60\% dos recursos alocados para a alimentação escolar para a aquisição de gêneros alimentícios da agricultura familiar. Produtos como leite integral pasteurizado tipo C, néctar de uva orgânica, geleia e doces de frutas orgânicas em pasta, doce de leite, ovos de galinha caipira e de codorna, mel em pote e em sachê, hortaliças e frutas (Turpin, 2009).

\section{Considerações finais}

Os resultados apresentados neste artigo mostram a visão do produtor familiar rural diante da normativa do PNAE. Ficou evidente que, embora alguns municípios brasileiros apresentem capacidade agrícola para fornecer gêneros alimentícios para o mercado escolar, os pequenos produtores rurais encontram dificuldades para acessar esse mercado e efetivar essa prática de forma regular e permanente. Questões como atrasos no pagamento, estrutura física inadequada e falta de transporte foram recorrentes nas falas. Embora boa parte dos agricultores já estivesse organizada em associações desde 2007, via PAA, a recente normativa do PNAE exige uma maior articulação, organização e planejamento entre o setor agrícola e as entidades executoras.

A lógica de comercialização do setor agrícola familiar é diferente das grandes empresas que são, historicamente, fornecedoras do PNAE. A agricultura tem estreita relação com os fatores climáticos, o que pode vir a demandar da gestão um melhor planejamento do tipo de produto, da sazonalidade dos alimentos e, consequentemente, de sua entrega nas escolas. Os agricultores organizados em associações que fornecem gêneros alimentícios semielaborados necessitam de recursos financeiros para qualificar sua produção no que se refere à estrutura física das cozinhas, que não comportam a demanda da entidade executora.

As mais recentes normativas do PNAE acreditam na importância do resgate de hábitos e costumes regionais, com produtos naturais, básicos e adaptados à cultura alimentar local. Porém, a maior parte dos gêneros alimentícios adquiridos dos agricultores familiares em Araripe é semielaborada, com produtos ricos em açúcar e gordura e que não fazem parte dos hábitos dos alunos. Pode-se supor que a dinâmica da comercialização desse tipo de produto com as escolas seja mais fácil quando comparada à dos alimentos in natura, que demandam estrutura como balanças, sacos plásticos, veículos com refrigeração.

Há que se pensar se, de fato, o pequeno produtor rural consegue acessar o mercado da alimentação escolar. A capacidade produtiva dos agricultores de regiões do interior do Ceará é, basicamente, de subsistência, para autoconsumo. Esse tipo de produtor, para conseguir escoar sua produção, necessita associar-se a mais agricultores em cooperativas ou associações, caso contrário, encontrará dificuldades que o afastarão desse mercado.

Mostra-se necessária, também, a realização de levantamentos periódicos sobre o potencial regional dos municípios para a produção local de gêneros alimentícios in natura, as principais culturas, a criação de animais e outros fatores. 0 desconhecimento pode estar favorecendo a compra de produtos semielaborados. Uma sugestão seria a realização de parcerias com universidades, órgãos como a Empresa de Assistência Técnica e Extensão Rural (Emater), a Empresa Brasileira de Pesquisa Agropecuária (Embrapa) e o Sebrae, para que esses dados fossem levantados e divulgados. Estabelecer, por exemplo, anual ou semestralmente, os alimentos da safra e entressafra, aqueles que mais sofrem variação de preço em relação ao clima e determinar qual é o potencial agrícola/agropecuário dos produtores da região, além de identificar quais deles têm potencial para atender à demanda em questão.

A recente normativa do FNDE apresenta um caráter complexo e multifuncional, o que torna necessário adotar ações intersetoriais para que essa dinâmica seja efetivada em todos os municípios brasileiros. Dessa maneira, os benefícios serão vol- 
tados não apenas aos alunos, que verão garantido seu direito a uma alimentação saudável, adequada e adaptada a seus hábitos alimentares, mas, também, aos agricultores familiares, que poderão comercializar seus produtos e reduzir os níveis de pobreza no meio rural.

\section{Contribuição dos autores}

Carvalho participou da concepção do tema, planejamento da pesquisa, delineamento metodológico e redação do artigo. Marques participou do planejamento da pesquisa, elaboração dos instrumentos, coleta, análise dos dados e redação do artigo. Gonçalves, Leite, Fernandes e Viana participaram da redação e revisão final do artigo.

\section{Referências}

ALMEIDA, V. E. S.; CARNEIRO, F. F.; VILELA, N. J. Agrotóxicos em hortaliças: segurança alimentar, riscos socioambientais e políticas públicas para promoção da saúde. Tempus: Actas em Saúde Coletiva, Brasília, DF, v. 4, n. 4, p. 84-99, 2009.

BARDIN, L. Análise de conteúdo. São Paulo: Edições 70, 2011.

BRASIL. Ministério da Saúde. Secretaria de Atenção à Saúde. Coordenação-Geral da Política de Alimentação e Nutrição. Guia alimentar para a população brasileira: promovendo a alimentação saudável. Brasília, DF, 2005. (Série A. Normas e Manuais Técnicos).

BRASIL. Decreto-Lei n ${ }^{0} 11.947$, de 16 de junho de 2009. Dispões sobre o atendimento da alimentação escolar e do Programa Dinheiro Direto na Escola aos alunos da educação básica.

Diário Oficial da União, Brasília, DF, 17 jun. 2009. Seção 3, p. 45.

BUAINAIN, A. M.; ROMEIRO, A. R.; GUANZIROLI, C. Agricultura familiar e o novo mundo rural. Sociologias, Porto Alegre, v. 5, n. 10, p. 312-347, 2003.
CARVALHO, D. G. Licitações sustentáveis, alimentação escolar e desenvolvimento regional: uma discussão sobre o poder de compra governamental a favor da sustentabilidade. Planejamento e Políticas Públicas, Brasília, DF, n. 32, p. 115-148, jun. 2009.

FNDE - FUNDO NACIONAL DE DESENVOLVIMENTO DA EDUCAÇÃO. Programa PNAE: alimentação escolar. Brasília, DF, 2013. Disponível em: <http://www.fnde.gov.br/ programas/alimentacao-escolar/alimentacaoescolar-apresentacao>. Acesso em: 18 fev. 2013.

GALLINA, L. S. et al. Representações sobre segurança alimentar e nutricional nos discursos de um conselho de alimentação escolar. Saúde e Sociedade, São Paulo, v. 21, n. 1, p. 89-102, 2012.

GUANZIROLI, C. E.; CARDIM, S. E. C. S. (Coord.). Novo retrato da agricultura familiar: o Brasil redescoberto. Brasília, DF: Incra, 2000.

Disponível em: <http://www.faser.org.br/anexos/ Retratodaagriculturafamiliar.pdf $>$. Acesso em: 13 jun. 2014 .

GUANZIROLI, C. E.; BUAINAIN, A. M.; DI SABBATO, A. Dez anos de evolução da agricultura familiar no Brasil (1996 e 2006). Revista de Economia e Sociologia Rural, Brasília, DF, v. 5o, n. 2, p. 351-370, 2012.

IBGE - INSTITUTO BRASILEIRO DE GEOGRAFIA E ESTATÍSTICA. Censo agropecuário 20o6. Rio de Janeiro, 2006.

KAGEYAMA, A.; HOFFMANN, R. Pobreza, segurança alimentar e saúde no Brasil. Campinas: Fundação Economia de Campinas, 2007.

MACIEL, L. R. Mercado institucional de alimentos: potencialidades e limites para a agricultura familiar. 2008. Dissertação (Mestrado em Agronegócios) - Faculdade de Agronomia e Medicina Veterinária da Universidade de Brasília, Brasília, DF, 2008.

MALUF, R. S. Segurança alimentar e nutricional. Petrópolis: Vozes, 2009. 
MARTINS, S. P.; CAVALCANTI, L. I. Avaliação do impacto da execução do PAA no Estado de Rio Grande do Norte. Sociedade e Desenvolvimento Rural, Brasília, DF, v. 1, n. 1, 2007. Disponível em: <http://www.inagrodf.com.br/revista/index.php/ SDR/article/view/27/24>. Acesso em: 5 set. 2014.

MINAYO, M. C. de S. O desafio do conhecimento: pesquisa qualitativa em saúde. São Paulo: Hucitec, 2010.

PREZOTTO, L. L. Uma concepção de agroindústria rural de pequeno porte. Revista de Ciências

Humanas, Florianópolis, v. 1, n. 31, p. 133-153, 2002.

SARAIVA, E. B. et al. Panorama da compra de alimentos da agricultura familiar para o Programa Nacional de Alimentação Escolar. Ciência \& Saúde Coletiva, Rio de Janeiro, v. 18, n. 4, p. 927-935, 2013.

SARTI, F. M.; CLARO, R. M.; BANDONI, D. H. Contribuições de estudos sobre demanda de alimentos à formulação de políticas públicas de nutrição. Cadernos de Saúde Pública, Rio de Janeiro, v. 27, n. 4, p. 639-647, 2011.
TEO, C. R. P. A.; MONTEIRO, C. A. Marco legal do Programa Nacional de Alimentação Escolar: uma releitura para alinhar propósitos e prática na aquisição de alimentos. Revista de Nutrição, Campinas, v. 25, n. 5, p. 657-668, 2012.

TRICHES, R. M.; SCHNEIDER, S. Alimentação escolar e agricultura familiar: reconectando o consumo à produção. Saúde e Sociedade, São Paulo, v. 19, n. 4, p. 933-945, 2010.

TURPIN, M. E. A alimentação escolar como fator de desenvolvimento local por meio do apoio aos agricultores familiares. Segurança Alimentare Nutricional, Campinas, v. 16, n. 2, p. 20-42, 2009.

VILLAR, B. S. et al. Situação dos municípios do estado de São Paulo com relação a compra direta de produtos da agricultura familiar para o Programa Nacional de Alimentação Escolar. Revista Brasileira de Epidemiologia, São Paulo, v. 16, n. 1, p. 223-226, 2013.

Recebido: 17/03/2013

Reapresentado: $24 / 12 / 2013$

Aprovado: 09/01/2014 